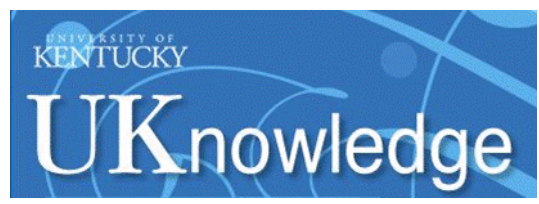

University of Kentucky

UKnowledge

$11-2009$

\title{
Adding Dental Therapists to the Health Care Team to Improve Access to Oral Health Care for Children
}

David A. Nash

University of Kentucky, danash@uky.edu

Follow this and additional works at: https://uknowledge.uky.edu/ohs_facpub

Part of the Dentistry Commons

Right click to open a feedback form in a new tab to let us know how this document benefits you.

\section{Repository Citation}

Nash, David A., "Adding Dental Therapists to the Health Care Team to Improve Access to Oral Health Care for Children" (2009). Oral Health Science Faculty Publications. 15.

https://uknowledge.uky.edu/ohs_facpub/15

This Article is brought to you for free and open access by the Oral Health Science at UKnowledge. It has been accepted for inclusion in Oral Health Science Faculty Publications by an authorized administrator of UKnowledge. For more information, please contact UKnowledge@lsv.uky.edu. 
Adding Dental Therapists to the Health Care Team to Improve Access to Oral Health Care for Children

Digital Object Identifier (DOI)

http://dx.doi.org/10.1016/j.acap.2009.08.005

Notes/Citation Information

Published in Academic Pediatrics, v. 9, no. 6, p. 446-451.

Copyright @ 2009 Academic Pediatric Association. Published by Elsevier Inc. All rights reserved.

This manuscript version is made available under the CC-BY-NC-ND 4.0 license

http://creativecommons.org/licenses/by-nc-nd/4.0/ 


\section{Copyright () 2009 Academic Pediatric Association. Published by Elsevier Inc. All rights reserved.}

This manuscript version is made available under the CC-BY-NC-ND 4.0 license http://creativecommons.org/licenses/by-nc-nd/4.0/ 


\section{Adding Dental Therapists to the Health Care Team to Improve Access to Oral Health Care for Children}

David A. Nash, D.M.D., M.S., Ed.D.

William R. Willard Professor of Dental Education Professor of Pediatric Dentistry

College of Dentistry

University of Kentucky

danash@email.uky.edu

Telephone: $859 / 323.2026$

Fax: 859/323.4685

Key Words: Oral Health, Access to Care, Disparities, Dental Therapist Abstract: 210 words Body: 3,882 words References: 1,761 words No conflicts of interest exist. 


\begin{abstract}
Oral Health in America: A Report of the Surgeon General, and the subsequent National Call to Action to Promote Oral Health, contributed significantly to raising awareness regarding the lack of access to oral health care by many Americans, especially minority and low income populations, with resulting disparities in oral health. The problem is particularly acute among children.
\end{abstract}

The current dental workforce in the United States is inadequate to meet the oral health care needs of children. It is inadequate in terms of numbers of dentists, as well as their geographic distribution, ethnicity, education, and practice orientation.

Dental therapists, paraprofessionals trained in a two academic year program of postsecondary education, have been employed internationally to improve access to oral health care for children. Research has documented that utilizing dental therapists is a cost effective method of providing quality oral health care for children. Dental therapists have recently been introduced in Alaska by the Alaska Native Tribal Health Consortium.

Dental therapists could potentially care for children in dental offices, public health clinics, and school systems, as well as in the offices of pediatricians and family physicians. Adding dental therapists to the health care team would be a significant strategy for improving access to care for children and reducing oral health disparities. 


\section{Introduction}

Oral Health in America: A Report of the Surgeon General, and the subsequent National Call to Action to Promote Oral Health, under the leadership of the Office of the Surgeon General, contributed significantly to raising awareness regarding the lack of access to care for many Americans, with the resultant existence of significant disparities in oral health. ${ }^{1,2}$ This article was prepared as a component of the American Academy of Pediatrics' review of progress in access to care and improving children's oral health since the Surgeon General's report. Nash and Nagel have reported that the vision for introducing the international model of dental therapists in the United States to care for children was a direct result of the Surgeon General's Report. ${ }^{3}$

While Oral Health in America addressed the issue of oral health for all Americans, this article will focus on the issue as related to children, and will: 1) identify workforce barriers that exist in providing access to oral health care for children; 2) characterize international approaches to improving access to care for children; 3 ) suggest that current approaches to care are not costeffective; 4) review the recent effort to introduce dental therapists in the United States; 5) identify a training strategy for dental therapists; and 6) suggest practice settings for dental therapists, including in the offices of pediatricians and family physicians. Throughout, justification will be advanced for adding dental therapists to the health care team in the United States to improve access to care for children and reduce oral health disparities.

\section{Workforce Barriers to Accessing Oral Health Care for Children}

Multiple barriers have been identified in ensuring access to care for children. ${ }^{1,2,4,5,6}$ Significant 
among these barriers is the professional dental workforce--inadequacy in the number of dentists, as well as their geographic distribution, ethnicity, education, and practice orientations.

There are approximately 130,000 actively practicing general dentists in the United States. ${ }^{7}$ The dentist/population is declining from its peak of 59.5/100,000 in 1991 and will drop from the current 58/100,000 to 52.7/100,000 in the year $2020 .^{8}$ Beginning in 2008 there are be more dentists retiring than graduating; this trend will continue until $2020 .{ }^{9}$ While there has been a significant increase in the number of pediatric dentists over the past 30 years, there are only 4,861 active members of the specialty organization, the American Academy of Pediatric Dentistry. ${ }^{10}$ In 2000, the president of the American Academy of Pediatric Dentistry, stated: “...even with a Herculean increase in training positions [for pediatric dentists], improved workforce distribution, and better reimbursement and management of public programs, pediatric dentistry [the specialty] will never be able to solve this national problem [of disparities] alone. We need help."11

Compounding the issue of numbers of dentist is the location of dental practices. The overwhelming majority of dentists practice in suburbia, with few practicing in rural and inner city areas where children with the greatest need live. The number of federally designated dental health professional shortage areas increased from 792 in 1993 to 4,091 in $2009 .{ }^{12,13}$

The ethnicity of oral health professionals contributes to the access problem. Ethnic populations prefer health professionals of the same ethnicity, and minority health professionals provide more care for the underserved. ${ }^{14,15}$ While approximately $12 \%$ of the population is African-American, only $2.2 \%$ of dentists are. Individuals of Hispanic ethnicity make up another $10.7 \%$ of the 
population, yet only $2.8 \%$ of dentists are Hispanic. ${ }^{16}$ Less than $6 \%$ of entering student dentists are African-American and less than $6 \%$ are Hispanic. ${ }^{17}$ The demographics of oral disease suggest that poor access to care among these two minority groups contribute significantly to the overall disparities in oral health among America's children. ${ }^{18}$

A further issue is the general lack of instruction and experience graduating general dentists have had in treating children. The typical college of dentistry curriculum provides an average of only 177 clock hours of didactic and clinical instruction in dentistry for children. ${ }^{19}$ A recent study entitled "U.S. Predoctoral Education: Its Impact on Access to Care," found that 33\% of dental school graduates had not had any actual clinical experience in performing pulpotomies and preparing and placing stainless steel crowns; common therapies required for treating dental caries in children. The authors concluded "results suggest that U.S. pediatric dentistry predoctoral programs have faculty and patient pool limitations that affect competency achievement, and adversely affect training and practice. ${ }^{.20}$ General dentists are not likely to practice what they not been taught, or in which they have not developed competencies during their dental education.

The practice orientation of many dentists is a barrier to access. Dentists generally do not treat publicly insured children, children covered by Medicaid or the Children's Health Insurance Program (CHIP). A 2001 study found that approximately 25\% of dentists received some payment from Medicaid during a given year; however, only $9.5 \%$ received $\$ 10,000$ or more. ${ }^{21}$ As a result of the recent expansion of the Children's Health Insurance Program, 40 million of America's 78.6 million children — the majority--are now covered by Medicaid and CHIP. ${ }^{22}$ 
Thus, over one half of American children are covered by public dental insurance-and these are the children in whom the overwhelming percentage of dental disease exists. ${ }^{18}$ Yet, less than $10 \%$ of dentists participate to any significant degree in caring for these children. A 2004 report indicated that only $45 \%$ of California's pediatric dentists participated in the state's Medicaid program. ${ }^{23} \mathrm{~A}$ recent national survey of board-certified pediatric dentists reported $53.2 \%$ of private practicing pediatric dentists accepted Medicaid reimbursement. ${ }^{24}$ These statistics document the significant problem of access to care for children from low income families.

\section{An International Approach for Improving Access to Care for Children}

In 1921, New Zealand developed a two academic year program to train high school graduates to become school dental nurses. ${ }^{25}$ These school dental nurses were then assigned to school-based dental clinics, which subsequently came to exist in all of the elementary schools of New Zealand. ${ }^{26,27}$ Today there are over 600 dental therapists (the name changed in the 1980s) caring for the country's 850,000 children. ${ }^{28} 97 \%$ of New Zealand's children are cared for by dental therapists who are assigned to every elementary and middle school in New Zealand. ${ }^{29}$ They work under the general supervision of a district dental officer. A recent report of the oral health of New Zealand's school children documented that at the end of a given school year essentially none of New Zealand's children in the School Dental Service had untreated tooth decay. ${ }^{30,31}$

The model developed in New Zealand has spread to 52 other countries of the world. ${ }^{28}$ Australia has over 1,500 practicing dental therapists, with $88 \%$ working in the School Dental Service. ${ }^{28}$ Malaysia employs dental therapists to provide publically financed dental care for its three million children through a network of 2,000 public dental clinics for children staffed by dental therapists. Essentially all dental care for children in Malaysia is by dental therapists. ${ }^{28}$ Dental therapists 
have practiced with Health Canada, Canada's Ministry of Health, since $1972 .{ }^{32,33}$ There are 300 dental therapists practicing in Canada, with approximately 100 employed by Health Canada to treat Canada's First Nation people. ${ }^{34,35}$ The remainder practice in Saskatchewan in dental offices complementing the work of dentists in much the same manner dental hygienists practice in the United States. There are 700 dental therapists practicing in the United Kingdom in a variety of oral health care settings. ${ }^{36}$ Great Britain recently expanded the training opportunities for dental therapists and now graduates over 200 dental therapists each year from its 15 programs. ${ }^{37,38}$ It is important to note that the history of dental therapists internationally is that care has been limited to children. Only recently have some jurisdictions begun to permit selected procedures to be performed on adults in specific circumstances. The research regarding dental therapists on quality, access, effectiveness and costs, as identified elsewhere in this article, has been in relationship to children, not adults.

Throughout the world the model of using dental therapists to provide primary care for children is growing in popularity, primarily because of a dental workforce unable to provide access to basic oral health care, particularly for children. International studies and experience, as well as research in the United States, have documented the quality of care dental therapists provide children in comparable to that of general dentists; quality in terms of diagnostic, preventive, and technical skills. $^{25,39-49}$

\section{The Economic Issue}

Developing and deploying dental therapists for children is rational economics. General dentists are trained in complex diagnostic and rehabilitative procedures for all patients; pediatric dentists are trained in primary care for children, but also in tertiary care --the ability to care for children 
with complex developmental and medical problems, as well as to manage children who either lack cooperative ability or are uncooperative in their behavior. General dentists' average earnings for 2006 were $\$ 224,190$, and pediatric dentists were $\$ 337,810 .^{7}$ In New Zealand, dental therapists with two years of post-secondary education treat essentially all of the nation's children and earn, on average, $\$ 40,000 /$ year (US) ${ }^{50}$ It is questionable as to whether the typical child requires the level of expertise of a dentist/pediatric dentist in receiving primary preventive and basic restorative care.

The division of labor principle of organizational management science suggests that procedures should be delegated to the least trained and lowest salaried individual in an organization who is able to effectively and competently perform the activity at the required level of quality. ${ }^{51}$ Applying this principle to the dental workforce suggests that primary preventive and basic restorative procedures for children should be assigned to a dental therapist, resulting in a more economical expenditure of resources. This is particularly relevant with regard to care paid for by Medicaid/CHIP, given significantly constrained public monies, and the inability of public insurance to reimburse practitioners at the rate of their usual and customary fees. As indicated, the majority of America's children are now covered by public insurance. There would be an important role for general dentists and pediatric dentists—serving as providers of secondary and tertiary care for children, as is the case in New Zealand and Australia; focusing on problems that cannot be managed by a dental therapist--problems that only a dentist can address.

\section{Introducing Dental Therapists in the United States}

Because of the prevalence of severe dental disease among Alaska Native children and the chronic shortage of dentists in Alaska, the Alaska Native Tribal Health Consortium, in 2003, 
with the support of the Indian Health Service, sent six Alaskans to be trained as dental therapists at the University of Otago, New Zealand's national dental school. ${ }^{3,52}$ They returned to Alaska in 2005 to begin caring for patients, primarily children, in rural villages, only to be met with a lawsuit by the American Dental Association (ADA) to stop what the Association considered to be the illegal practice of dentistry. ${ }^{53}$, The Alaska attorney general's office subsequently issued a ruling that dental therapists in the Alaska tribal health system are not subject to the state dental practice act because they are certified under federal law. ${ }^{54}$ An independent assessment of the quality of care provided by the first cohort of Alaskan dental therapists returning from New Zealand concluded that they met every standard of care evaluated and were "competent providers. ${ }^{" 55}$ Subsequent research of the competency of the Alaskan dental therapists concluded: "No significant evidence was found to indicate that irreversible dental treatment provided by DHATs [dental therapists] differs from similar treatment provided by dentists. ${ }^{" 56}$ The lawsuit brought by the ADA was settled in $2007 .{ }^{57,58}$ Currently, eleven dental therapists are practicing in Alaska who were trained in New Zealand. ${ }^{28}$ Training of dental therapists has been initiated in Alaska in a program in cooperation with the physician's assistant program of the School of Medicine at the University of Washington. ${ }^{59}$ The American Association of Public Health Dentistry and the American Public Health Association have endorsed the practice of dental therapists in Alaska. ${ }^{60,61}$

A major objection to the introduction of dental therapists to the United Sates is the belief that dental therapists are not adequately trained to care for children. ${ }^{62}$ However, the results are uniform in finding that dental therapists provide an equivalent quality of care as dentists. ${ }^{33,39-49}$ The typical two year dental therapy curriculum internationally is 2,400 clock hours- - two academic years. ${ }^{28}$ Traditionally, dental therapists have only provided care for children, so 
curriculum time is devoted specifically to learning to care for children. In New Zealand, 760 of these hours are spent in the clinic caring for children. ${ }^{63}$ As indicated previously, the most recent study of the curriculum hours in our nation's dental schools preparing general dentists indicates that an average of only 177 hours is spent teaching general dentists to care for children; this includes classroom and clinic. At least from the perspective of the instructional curriculum, dental therapists receive more technical training and experience in treating children than do general dentists.

\section{Developing Dental Therapists}

Various models are possible for developing dental therapists to treat children in the United States. The classical model in the world has been a two year training program similar to current two year dental hygiene training programs in the U.S. However, the leadership of dental education in Australia, New Zealand, and Great Britain have concluded that integrating the curricula for training dental hygienists and dental therapists results in a more versatile member of the health care team, and is more economical than maintaining separate programs. They have now integrated their previously independent two year therapy and hygiene programs into a three year program, with resulting credentialing in both fields of practice.

Much of the curriculum of the current dental hygiene programs in the United States is inclusive of the biomedical and dental courses of traditional international dental therapists' programs. Few additional competencies would need to be added to the hygienists' curriculum to qualify a dental hygienist to provide the services traditionally provided by dental therapists for children. Research in the United States in the 1970s at the Forsyth Institute, the University of Kentucky, 
and at the University of Iowa, has demonstrated that dental hygienists can be trained in a relatively short period of time to provide basic, primary care for children; certainly within one additional academic year and potentially less. ${ }^{64,65,66}$

It would be possible to develop an integrated, but modular, curriculum of three years in which the first year is shared by both hygienists and therapists, with individuals tracking to either dental therapy or dental hygiene in the second year. Upon completing the two year curriculum they could gain licensure in their respective field. Individuals wanting to be dually qualified could, in a third year, cycle through the second year curriculum in which they had not previously participated.

The advantages of such an integrated, modular model include: Accessibility-The curriculum could be offered in the over 250 associate degree dental hygiene programs that exist in community and technical colleges in every state, thus permitting ready access to potential students. ${ }^{67}$ Flexibility-Individuals could choose to become hygienists or therapists, or both. This approach would also facilitate graduated hygienists returning to training for one year to gain qualification in the competencies associated with dental therapy. Such an opportunity would help address an issue that has been in the forefront of dental hygiene for some time, enriching professional life with new skills. Economical — Integrated training could utilize existing faculty, programs, and facilities, thus minimizing expensive duplication. Rapid and Ready

Implementation - A therapist's curriculum, based on the international model, could be developed expeditiously, and with faculty and facilities already in place could result in therapists being ready to help address the access problem for children in a relatively brief period. 


\section{Practice Settings for Dental Therapists}

Children should be engaged in environments in which they normally function, if the access problem is to be ideally addressed. New Zealand, from the beginning of its development of the concept of a school dental nurse/therapist, identified the school system as the best place to capture this audience. New Zealand established dental clinics in its schools where school dental therapists effectively care for school-age children, as well as infants, toddlers and preschool children in the neighborhood.

The New Zealand school dental therapist assigned to a neighborhood school functions as what has been recently identified in the United States as a "dental home." In 2002, the concept of the dental home was introduced in the dental literature. ${ }^{68}$ The dental home is based on the American Academy of Pediatrics" "medical home." Among the characteristics of both is that care for children is to be accessible, coordinated, and continuous. The American Academy of Pediatric Dentistry's definition of a dental home states: "The dental home is the ongoing relationship between the dentist and the patient, inclusive of all aspects of oral health care delivered in a comprehensive, continuously accessible, coordinated, and family-centered way. Establishment of a dental home begins no later than 12 months of age and includes referral to dental specialist when appropriate." ${ }^{\prime 9}$ It is difficult to envision a dental home being provided to all of America's children, and by 12 months of age, considering the identified current workforce limitations associated with general dentists and pediatric dentists. However, with the significant problem of early childhood caries, it is important that parents receive anticipatory guidance and preventive care early in a child's life; as the dental home definition states, by age one year. 
The New Zealand School Dental Service cares for over $97 \%$ of all elementary school children, and $56 \%$ of its preschool children, because care is brought to them in their neighborhood schools. ${ }^{70}$ School-based dental therapists in Australia provide the overwhelming majority of care for children in Australia. ${ }^{71}$ However, school-based health care is not the norm in the United States. The offices of pediatricians and family physicians currently serve as medical homes for the overwhelming majority of America's children. Increasingly, oral health is understood as a vital component of general health and well being. It is not unreasonable to envision physicians enlarging their function to provide a "health home" for children that includes oral health. The majority of children are seen regularly by the nation's 57,000 pediatricians and over 60,000 family physicians. ${ }^{72,73}$ The typica01 infant/child has had 12 visits to the pediatrician/family practice physician by age three; providing multiple opportunities for anticipatory guidance, as well as early intervention to effect primary preventive and basic restorative oral health care. ${ }^{74}$ Sixty percent of children's visits to the physician are in pediatricians' offices and approximately $20 \%$ in the offices of family physicians. ${ }^{75}$ These primary care physicians could expand their scope of practice and retain dental therapists to work in their offices under their supervision. The medical and dental practice acts in a number of states would permit them to do so.

In 2003, the Public Health Practice Office of the Centers for Disease Control funded a study of the dental practice acts of all 50 states and the District of Columbia to determine the limitations the individual state practice acts place on individuals other than licensed dentists to provide oral health care. ${ }^{76}$ The results of the study suggest there would be no restrictions on physicians, such as pediatricians and family practice physicians, providing dental care in 23 states; and no restrictions in an additional 11 states as long as dentistry was not practiced as a specialty. In nine 
states, physicians would only be allowed to provide emergency care. Three additional state practice acts seemed to suggest physicians would be restricted from providing any oral health services.

It is interesting to speculate what could occur if pediatricians and/or family practice physicians were to retain dental therapists trained internationally and began to offer primary oral health care for children in their offices. Such would seem to be permissible in 23 states, and possibly in as many as 34 , depending on how "not practicing dentistry as a specialty" is interpreted. Certainly there are economic incentives for doing so. In 2006, the average general pediatrician earned $\$ 188,496 /$ year, ${ }^{77}$ and a family physician earned $\$ 161,000 /$ year. ${ }^{73}$ As indicated previously, the average pediatric dentist had a net income of $\$ 337,810$ in 2006 . Such a discrepancy in income is related to the number of technical procedures that are reimbursable to pediatric dentists, many of which a dental therapist could perform.

Pediatricians and family physicians are now receiving training in oral health care in a number of settings around the country and are conducting oral exams and applying fluoride varnish to children's teeth, for which they are being remunerated. ${ }^{78}$ Oral health is a strategic priority for the American Academy of Pediatrics (AAP). ${ }^{72}$ The AAP's Oral Health Initiative has a significant training program for pediatricians and other child health professionals at its website.

(www.aap.org/oral health/cme) The Society of Teachers of Family Medicine Group on Oral Health has developed a national oral health curriculum "Smiles for Life," for educating family physicians. (www.smilesforlife2.org.) 
While a physician would typically not have the expertise in dentistry to 'supervise' specific dental procedures, it should be noted that dental therapists caring for children in other countries, such as New Zealand and Australia, do not practice with direct supervision of a dentist. A physician-led "health home" could refer to dentists those children whose care exceeded the competencies and scope of practice of a dental therapist. It should be anticipated that integrating primary prevention and basic restorative dental care for children in the offices of pediatricians and family physicians using dental therapists would be met with significant opposition for the dental practice community. However, were such a delivery system in place, most all infants/children could have access to care to address the problem of early childhood caries, and help ensure a head start to good oral health.

In the more traditional delivery system, dental therapists would be in demand in dental practices as dental hygienists are today. Adding a therapist to the health care team could result in an increase in the numbers of dentists providing care for children, as well as expand the capacity for dentists already caring for children to see more children. Most dentists do not accept children in their practices whose care is publicly insured, ostensibly due to the inability to manage the costs of care given overhead considerations and the lower reimbursement schedule. Dental therapists could help mitigate this issue as care could potentially be provided in a more cost-effective manner. Therapists could also practice in the public sector in public health clinics, federally qualified community health centers, and with not-for-profit organizations. However, state dental practice acts and regulations would have to be revised for dental therapists to practice in any of these settings. 


\section{Conclusion}

Inadequate access to oral health care for America's children has been documented, with resultant disparities in oral health among children. Children from low income families and minorities experience more oral disease and receive less care. The current dental workforce is inadequate in numbers, composition, geographic location, education, and orientation to address this problem. Other countries in the world have utilized paraprofessionals, dental therapists, individuals trained in two year programs of post-secondary education, to provide primary preventive and basic restorative care for children. The care provided by dental therapists has been documented to be equivalent in quality to that of dentists, and is more economical. Developing dental therapists is a significant strategy to improve access to care for America's children and reduce oral health disparities. Dental therapists practicing in the offices of pediatricians and family physicians could offer the advantage of helping ensure access to oral health care from infancy for the majority of America's children. 


\section{References}

1. U. S. Department of Health and Human Services. Oral health in America: a report of the surgeon general. Rockville, Maryland: U.S. Department of Health and Human Services, National Institute of Dental and Craniofacial Research, National Institutes of Health, 2000:308 pages.

2. U. S. Department of Health and Human Services. National call to action to promote oral health: A public-private partnership under the leadership of the office of the surgeon general. Rockville, Maryland: U.S. Department of Health and Human Services, National Institute of Dental and Craniofacial Research, National Institutes of Health, 2003:28 pages.

3. Nash, DA, Nagel, RJ. A brief history and current status of a dental therapy initiative in the United States. J Dent Educ 2005;69(8):857-859.

4. Gehshan S, Straw T. Access to oral health services for low-income people: Policy barriers and opportunities for intervention for the Robert Wood Johnson Foundation. Forum for State Health Policy Leadership/National Council of State Legislatures, 2002:25 pages.

5. Improving the oral health status of all Americans: Roles and responsibilities of academic dental institutions. Washington, DC: American Dental Education Association, 2003:22 pages.

6. Oral health: factors contributing to low use of dental services by low-income populations. Washington, DC: General Accounting Office, 2000:41. 
7. American Dental Association, 2007 Survey of Dental Practice: Income from the private practice of dentistry. American Dental Association, Chicago, Illinois, 2009.

8. American Dental Association, Division of Education, 2006-2007 Report, American Dental Association, Chicago, Illinois, 2008.

9. Beazoglou T, Bailit H, Brown J. Selling your practice: are there problems ahead? J Am Dent Assoc. 2000;131(12):1693-1698.

10. American Academy of Pediatric Dentistry: www.aapd.org, Accessed July 7, 2009.

11. Casamassimo P. We need help! Pediatric Dentistry Today. American Academy of Pediatric Dentistry. 2000, 30 pages.

12. U.S. Department of Health and Human Services, Health professions shortage areas. Rockville, MD: Health Resources and Services Administration, 1999.

13. U.S. Department of Health and Human Services, Health Resources and Services Administration. http://bhpr.hrsa.gov/shortage. Accessed July 7, 2009.

14. Xu G, Fields SK, Laine C, Veloski JJ, Barzansky, B, Martine CJM. The relationship between the race/ethnicity of generalist physicians and their care for underserved populations. Am J Public Health 1997;87:817-822.

15. Komaromy M, Grumbach K, Drake M, et al. The role of black and Hispanic physicians in providing health care for underserved populations. N Engl J Med 1996;334:1305-1310.

16. Brown LJ, Lazar V. Minority dentists—why we need them: Closing the gap. Washington, DC: Office of Minority Health, U.S. Department of Health and Human Services, 1999:6-7.

17. Valachovic RW. Dental workforce trends and children. Ambul Pediatr 2002; (Suppl 2):154-161. 
18. Kaste LM, Selwitz RH, Oldakowski JA, Brunelle JA, Winn DM, Brown LJ. Coronal caries in the primary and permanent dentitions of children and adolescents 1-17 year of age: United States, 1988-91. J Dent Res 1996;75:631-41.

19. American Dental Association, Survey of Dental Education, 2006. Chicago, Illinois, 2008.

20. Seale NS, Casamassimo P. U.S. predoctoral education in pediatric dentistry: Its impact on access to dental care. J Dent Educ 2003;67(1):23-30.

21. Gehshan S, Hauck P, Scales J. Increasing dentists' participation in Medicaid and SCHIP. Forum for State Health Policy Leadership. National Conference of State Legislatures, Denver and Washington: 2001:20 pages.

22. Henry J. Kaiser Family Foundation, Medicaid/CHIP, www.kff.rog/medicaid Accessed July 9, 2009.

23. Morris, PJ, Freed, JR, Nguyen A. Duperon DF, Freed BA, Dickmeyer J. Pediatric dentists' participation in the California Medicaid program. Pediatr Dent 2004;26:79-86.

24. Slonkosky PW, Nash, DA, Mathu-Muju, KR, Haney, CA, Bush, HH. A practice profile of board-certified pediatric dentists based upon characteristics of the dental home. Submitted, Pediatr Dent, July, 2009. IADR Abstract \#2473, Miami, Florida, April, 2009.

25. Fulton JT. Experiment in dental care: results of New Zealand's use of school dental nurses. Geneva, Switzerland: World Health Organization, 1951.

26. Nash, DA. Developing a pediatric oral health therapist to help address oral health disparities among children. J Dent Educ 2004;68(1):8-20.

27. Nash, DA. Developing and deploying a new member of the dental team: a pediatric oral health therapist. J Pub Health Dent 2005;65(1):48-55. 
28. Nash DA, Friedman JW, Kardos TB, et al. Dental therapists: a global perspective. Int Dent J 2008;58(2):61-70.

29. New Zealand Ministry of Health. www.moh.govt.nz. Accessed March 1, 2007.

30. Improving child oral health and reducing child oral health inequalities: report to the minister from the Public Health Advisory Committee. Wellington, New Zealand: National Health Committee, 2003:94 pages.

31. Thomson WM. associate professor, dental public health, School of Dentistry, University of Otago, Dunedin, New Zealand. Personal communication, May 2003.

32. Davey K. Dental therapists in the Canadian north. J Can Dent Assoc 1974;40:287-291.

33. Schnell GM. The federal dental therapy program: a dream and the reality. Unpublished manuscript, 22 pages.

34. Saskatchewan Dental Therapists Association Registrar Report, 2007.

35. White L. National Dental Therapy Program Officer, Health Canada, personal communication, March, 2007.

36. Annual Report, 2005, General Dental Council, London, England, 2006.

37. Education and Training of Personal Auxiliary to Dentistry. The Nuffield Foundation, 1993.

38. British Association of Dental Therapists' website: www.badt.org.uk. Accessed January $11,2007$.

39. Ambrose ER, Hord AB, Simpson WJA. Quality evaluation of specific dental services provided by Saskatchewan dental plan: final report. Regina, Saskatchewan, 1976. 
40. Crawford PR, Holmes, BW. An assessment and evaluation of dental treatment in the Baffin Region. A report to the Medical Services Branch of National Health and Welfare, January 25, 1989.

41. Trueblood RG. A quality evaluation of specific dental services provided by Canadian dental therapists. Medical Services Branch, Epidemiology and Community Health Specialties, Health and Welfare Canada. Undated, 14 pages.

42. Trueblood RG. An analytical model for assessing the costs and benefits of training and utilizing auxiliary health personnel with application to the Canadian dental therapy program. Montreal: Department of Health Technology, Concordia University, 1992.

43. Bradlaw R, Douglas THT. Roper-Hall HT, et al. Report of United Kingdom mission on New Zealand School Dental Service. NZ Dent J 1951;47(228):62-78.

44. Friedman JW. The New Zealand School Dental Service: A lesson in radical conservatism. J Amer Dent Assoc 1972;85(3):609-617.

45. Redig D, Dewhirst F, Nevit G, et al. Delivery of dental services in New Zealand and California S Calif Dent Assoc 1973;41(4):318-321.

46. Roder DM. The effect of treatment provided by dentists and school dental therapists in the South Australian School Dental Service. Aust Dent J 1973;18(5):311-319.

47. Roder DM. The effect of treatment provided by dentists and school dental therapists in the South Australian school dental service. The second report. Aust Dent J $1976 ; 21(2): 147-152$.

48. Roder DM. Diagnosis, treatment planning and referral by school dental therapists. Aust Dent J 1974;19(4):242-249. 
49. Riordan PJ, Espelid I, Tveit AB. Radiographic interpretation and treatment decisions among dental therapists and dentists in Western Australia. Community Dent Oral Epidemiol 1991;19(5):268-271.

50. Kardos TB. Deputy Dean, School of Dentistry, University of Otago, Dunedin, New Zealand. Personal communication, June 6, 2008.

51. Gibson J, Ivancevich J, and Donnelly J, Jr. Organizations: Behavior, Structure, Processes. McGraw-Hill/Irwin, 2002.

52. Nash, DA, Nagel, RJ. Confronting oral health disparities among American Indian/Alaska Native Children: The pediatric oral health therapist. Amer J of Public Health. 2005;95(8):1325-1329.

53. American Dental Association. House of Delegates Proceedings. ADA Annual Session. Chicago, IL, 2000.

54. Memorandum to Robert E. Warren, Alaska Board of Dental Examiners from Paul R. Lyle, Sr. Attorney General, State of Alaska, Department of Law. Subject: State Licensure of Federal Dental Health Aides, 16 pages.

55. Fiset L. A report on quality assessment of primary care provided by dental therapists to Alaska natives. Submitted to the Alaska Native Tribal Health Consortium, September 30, 2005.

56. Bolin, KA. Assessment of treatment provided by dental health aide therapists in Alaska: A pilot study. J Amer Dent Assoc 139:1530-1539, 2008

57. Anchorage Daily News. Alaska lawsuit dropped. July 12, 2007.

58. American Dental Association. ADA News, ADA reaches settlement in Alaska litigation. July 16, 2007. 
59. Anchorage Daily News. Dental therapist training program opens in Alaska, January 16, 2007.

60. American Association of Public Health Dentistry. Resolution on the need for formal demonstration projects to improve access to preventive and therapeutic oral health services. 2006.

61. American Public Health Association. Resolution on dental therapists in Alaska. 2006.

62. To'olo G, Nash DA, Mathu-Muju KR. Haney C. Mullins MR, Bush, HM. Pediatric dentists' knowledge and opinions about pediatric oral health therapists. Submitted to Pediatr Dent, July, 2009. www.iadr.com/confex.com/iadr/2009/Miami/webprogram. Accessed April 2, 2009.

63. Tane, H. Director, Dental therapy program, School of Dentistry, University of Otago, Dunedin, New Zealand. Personal communication. May, 2003.

64. Lobene R. The Forsyth experiment: an alternative system for dental care. Cambridge, Massachusetts: Harvard University Press, 1979.

65. Spohn EE, Chiswell, LR, Davison DD. The University of Kentucky experimental duties dental hygiene project. Lexington, Kentucky, University of Kentucky, 1976. Unpublished report.

66. Sisty NL, Henderson, WG, Paule CL, Martin JF. Evaluation of student performance in the four-year study of expanded functions for dental hygienists at the University of Iowa. J Amer Dent Assoc 1978;97:613-627.

67. Nash, DA. Expanding dental hygiene to include dental therapy: Improving access to care for children, J Dent Hyg 84 (1):36-44, 2009. 
68. Nowak AJ, Casamassimo PS. The dental home. A primary care oral health concept. J Am Dent Assoc 2002;133:93-98

69. American Academy of Pediatric Dentistry. Definition of the dental home. Pediatr Dent 2008;28 (suppl):10

70. New Zealand Ministry of Health Toolkit: Oral Health. www.newhealh.govt.nz/toolkits/oralhealth Accessed March 1, 2007.

71. Teusner DN, Spencer AF. Dental therapist labour force, Australia, 2003. AIHW Dental Statistics and Research Series No. 29, Canberra, 2003.

72. American Academy of Pediatrics. www.aap.org. Accessed July 7, 2009.

73. Facts about family medicine, American Academy of Family Practitioners. Accessed July 7, at www.aafp.org .

74. American Academy of Pediatrics. Recommendations for preventive practice health care. Pediatrics. 2000;105:626, and American Academy of Pediatrics, Recommendations for Preventive Pediatric Health Care www.brightfutures.aap.org, accessed July 7, 2009.

75. Phillips RL, Basemore AW, Dodoo MS, Shipman SA, Green LA. Family physicians in the child health care workforce: Opportunities for collaboration in improving the health of children. Pediatrics 2006;118:1200-1206.

76. Center for Health Services Research and Policy. The effects of state dental practice laws allowing alternative models of preventive oral health care delivery to low income children. Center for Health Services Research and Policy, School of Public Health and Health Services, George Washington University Medical Center, Washington, D.C., 2003. 
77. Medical Group Management Association. www.mgma.com. Accessed on July 7, 2009 by Ms. Wendy Nelson, staff member of the American Academy of Pediatrics.

78. Cantrell C. Physicians' role in children's oral health. Portland (ME): National Academy for State Health Policy. Cited in Gehshan S., and Snyder, A. Why public policy matter in improving access to dental care. Dent Clin N Am, July 2009;53:573-589. 